\title{
A Study on Generation and Development Mechanisms of Fire Whirls \\ Part 1 Experimental Analysis using the Reductive Scale Model
}

\author{
Ken Matsuyama ${ }^{1}$, Naohisa Ishikawa ${ }^{1}$, Yoshifumi Ohmiya ${ }^{1}$, Shu-ichi Tanaka ${ }^{1}$, \\ Futoshi Tanaka ${ }^{1}$ and Yoshihiko Hayashi ${ }^{2}$ \\ ${ }^{1}$ Tokyo University of Science \\ ${ }^{2}$ Building Research Institute
}

Keywords : Fire Whirl, Scale Model, PIV, Height of Swirling Flame, Axial Temperature of Flame, Swirling Velocity

\section{INTRODUCTION}

"Fire Whirl" is a unique phenomenon that occurs in large-scale fires and causes catastrophic damage when it occurs in urban areas.[1, 2] Considerable experimental and theoretical research has been conducted on the basis of past fire whirl disasters in order to clarify the mechanism that causes fire whirls. [3, 5] However, it is difficult to define the generation mechanism and the characteristics of fire whirls, since they are often caused by and associated with various contingencies, such as weather conditions. Therefore, an experiment was conducted for the purpose of understanding the qualitative and quantitative aspects of the generation mechanism and the characteristics of fire whirls. The first step of this experiment involved assembling a scale model, and the experiment was reproduced by CFD model.

\section{EXPERIMENTAL SUMMARY}

External forces, such as meteorological phenomena and the turning force attributed to the Coriolis acceleration caused by the rotation of the Earth, could be considered as contributing to the generation of large-scale fire whirls that caused extensive damage in the past. However, such external forces were ignored in this experiment, which was conducted in the full-scale fire experiment facility of the National Building Research Institute of Japan.

\subsection{Experimental method and equipment}

The swirling flame was coercively yielded by installing a partition resembling the perimeter of a building that surrounds a fire source (Figure 1). As shown in Figure 1, the experiment was systematically implemented by changing the following four parameters: 1) heat release rate of the fire source, 2) gap between the partitions, 3) distance between 
the fire source and the partitions, and 4) height of the partitions. A propane gas burner $(200 \times 200 \mathrm{~mm})$ was used as the fire source.

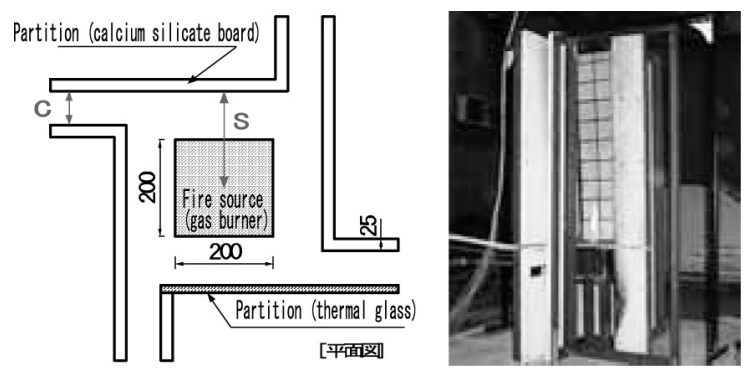

Figure 1 Conceptual diagram of the experimental equipment (Layout of the partition and the fire source) [units: $\mathrm{mm}$ ]

\subsection{Measurement parameters}

Temperature of the swirling flame: The temperature of the flame was measured using thermocouples (K type: $\phi 0.65[\mathrm{~mm}]$ ). The temperature distribution was measured by installing thermocouples at 48 points on the vertical axis in the vicinity of the burner (Figure 2).

Height of the swirling flame: Thermal glass was installed on one of the sides of the partitions in order to measure the height of the swirling flame, and a video camera was used for recording it.

Flow velocity on the horizontal plane of the flame: The flow velocity on the horizontal plane of the flame was measured using a Particle Image Velocimetry (PIV) system. The following equipment was used in this experiment.

\section{- Camera: KODAK MEGAPLUS Camera Model ES 1.0 \\ - Laser: Pulsed YAG Laser 2D (Japan Laser Corp) \\ - Analysis software: VidPIV (Oxford Lasers)}

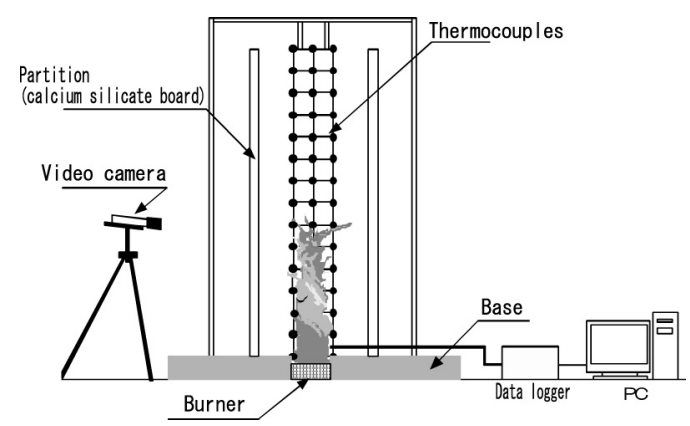

Figure 2 Positions of the thermocouples ( $y$-z plane) 


\subsection{Experimental conditions}

Table 1 shows the details of the experimental conditions.

Table 1 Experimental conditions

\begin{tabular}{|l|c|}
\hline \multicolumn{1}{|c|}{ Item } & Condition \\
\hline Heat release rate $(Q)[\mathrm{kW}]$ & $10,15,20$ \\
\hline $\begin{array}{l}\text { Distance between the fire source } \\
\text { and the partitions }(s)[\mathrm{m}]\end{array}$ & $\begin{array}{l}0.10 \text { to } 0.46 \\
\text { (Interval: } 0.02)\end{array}$ \\
\hline Gap between the partitions $(c)[\mathrm{m}]$ & $0.05,0.10,0.15$ \\
\hline Height of the partition $(h)[\mathrm{m}]$ & $0.5,1.0,1.5$ \\
\hline
\end{tabular}

(Wind-free environment)

\section{EXPERIMENTAL RESULTS}

\subsection{Height of the swirling flame}

Figures 4 and 5 are graphs indicating the height of the swirling flame for the cases where the gap between the partitions $(c)$ was changed and the cases where the distance between the fire source and the partitions was changed, respectively. The mean value of the height $H$ of the fire whirls, that is, the height of the flame including the flame tip, was determined by measuring the temperature every 0.03 seconds for 6 seconds.

As shown in Figure 4, the height of the swirling flame becomes lower as the gap between the partitions becomes wider. On the other hand, as shown in Figure 5, the height of the whirls becomes higher as the distance between the center of the fire source and the partitions becomes wider.

\subsection{Temperature distribution}

The mean value of the temperature distribution was determined by measuring the temperature every 2 seconds for 60 seconds. Figure 6 shows a typical example of the temperature distribution for each heat release rate. According to these results, the swirling induced constriction at a height of $0.4 \mathrm{~m}$ from the surface of the burner, and the whirling became stable regardless of the heat release rate.

\subsection{Swirling velocity}

The flow velocity distribution was measured on the horizontal plane of the partition using a PIV system. The height reading $(h r)$, measured from the floor, was at two points $(0.1 \mathrm{~m}$ and $0.3 \mathrm{~m})$, and was measured for 5 seconds at four frames per second. Figure 7 is a typical example of the mean velocity distribution over 5 seconds $(Q: 20 \mathrm{~kW}, h: 1.5 \mathrm{~m}, c$ : $0.05 \mathrm{~m}, s: 0.34 \mathrm{~m}$ and $0.40 \mathrm{~m}, h r: 0.1 \mathrm{~m})$. Figure 8 shows the mean velocity with respect to the distance between the fire source and the partitions $(h r)$. 
It can be inferred on the basis of Figures 7 and 8 that the mean velocity tends to increase as the distance between the fire source and the partitions $(s)$ becomes wider. The height of the swirling flame also tends to become higher as the distance $(s)$ becomes wider, and this tendency implies that the whirling flame becomes more stable as $s$ increases.

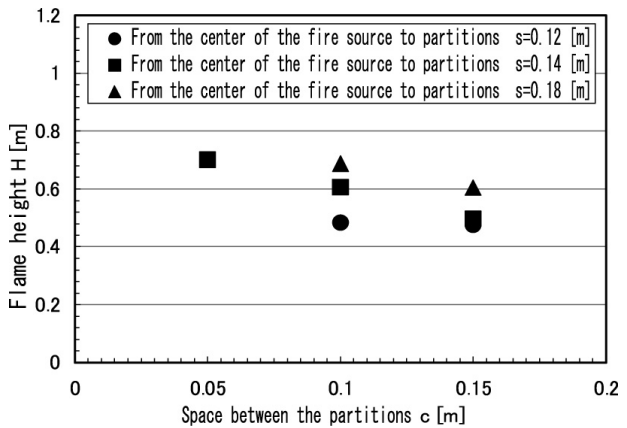

Figure 4 Height of swirling flame ( $Q: 15[\mathrm{~kW}], \mathrm{h}: 1.5[\mathrm{~m}], \mathrm{s}: 0.12$ to $1.18[\mathrm{~m}]$ )

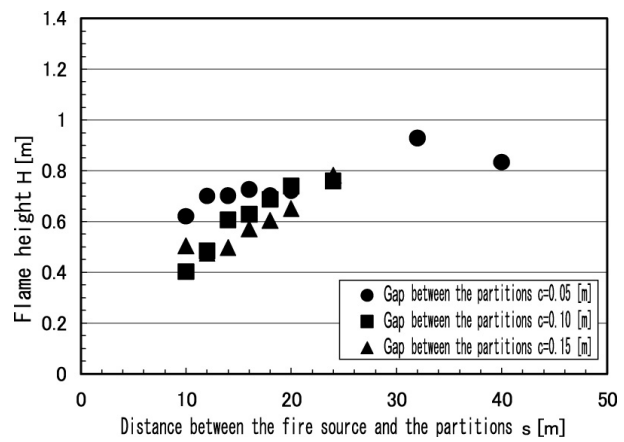

Figure 5 Height of the swirling flame ( $Q: 15[\mathrm{~kW}], \mathrm{h}: 1.5[\mathrm{~m}], \mathrm{c}: 0.05$ to $0.15[\mathrm{~m}]$ )
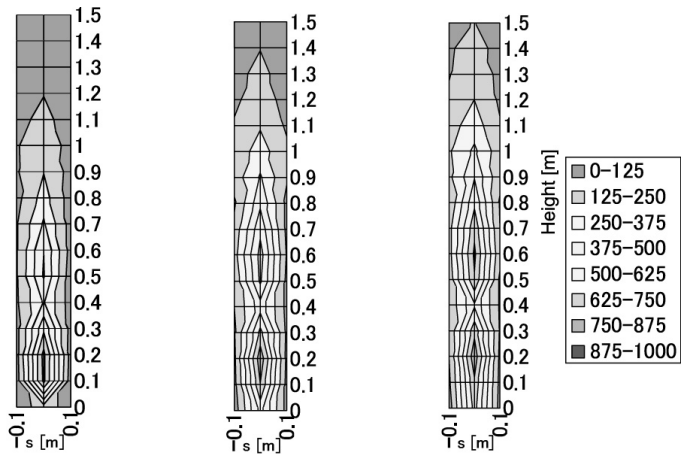

$(\mathrm{Q}=10[\mathrm{~kW}])$

$(\mathrm{Q}=15[\mathrm{~kW}])$

$(\mathrm{Q}=20[\mathrm{~kW}])$

Figure 6 Temperature distribution ( $Q: 1.5[\mathrm{~kW}], \mathrm{h}: 0.24[\mathrm{~m}], \mathrm{c}: 0.06[\mathrm{~m}]$ ) 


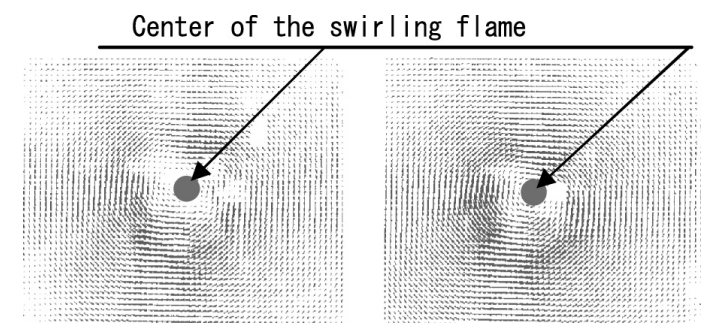

Figure 7 Velocity distribution (Left: $s=0.34[\mathrm{~m}]$, Right: $=0.40[\mathrm{~m}]$ )

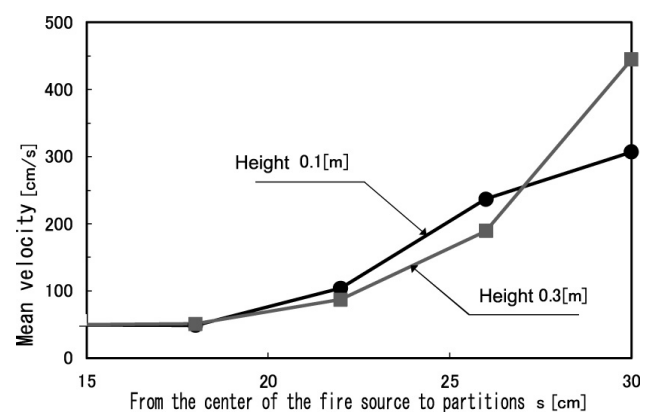

Figure 8 Velocity distribution ( $Q: 20[\mathrm{~kW}], \mathrm{h}: 1.5[\mathrm{~m}], \mathrm{c}: 0.05[\mathrm{~m}]$ )

\section{CONCLUSION}

This experiment was conducted in order to understand both the qualitative and quantitative aspects of the fire whirl generation mechanism, as well as its characteristics. This experiment was conducted systematically, with the use of a controlled fire source that was surrounded by four lateral partition walls in a calm environment, by tuning four parameters, namely the heat release rate of the fire source $(Q)$, the gap between the partitions $(c)$, the distance between the fire source and the partitions $(s)$ and the height of the partitions $(h)$. Consequently, the following results were obtained:

- The height of the swirling flame becomes lower if $h$ and $c$ are greater and $s$ is smaller.

- Considering the temperature of the swirling flame, the swirling induced a constriction at a certain height (where the temperature becomes lower).

- The mean velocity on the horizontal plane of the flame tends to increase as the distance between the fire source and the partitions $(s)$ becomes greater.

\section{REFERENCES}

1. Soma S., "Whirl with Conflagration -A Study on Whirl at Remains of Relocated Clothing Factory-", Journal of Japan Association for Fire Science and Engineering, Vol.24, No.2, pp.119-129, 1974 (in Japanese) 
2. Soma S., "Handbook of Fire New Edition", pp.274-279, 1984 (in Japanese)

3. Sato K. and K.T.Yang, "Study of Fire Whirl", Journal of Japan Society of Fluid Mechanics, Vol.19, pp.81-87, 2000

4. Sahto K, K.T.Yang, "Simulations of Swirling Fires Controlled by Channeled Self-generated Entrainment Flows", Proceedings of the 5th International Symposium on Fire Safety Science, pp.201-212, 1997

5. Hasemi Y., "Modeling of the Flame-Cored Fire Whirl", Journal of architecture, planning and environmental engineering. Transactions of AIJ, No.352, pp.119-124, 1985 (in Japanese)

\section{SYMBOLS}

$D$ : Length of one side of the fire source $[\mathrm{m}]$

$c$ : Gap between partitions $[\mathrm{m}]$

$H$ : Height of the whirling flame [m]

$h:$ Height of the partition [m]

$h r:$ Position where velocity was measured [m]

$Q:$ Heat release rate $[\mathrm{kW}]$

${ }_{s}$ : Distance between the fire source and the partitions [m]

This experiment was founded by Grants-in-Aid for Scientific Research (Exploratory Research) 2003 (MEXT of Japan). 